\title{
Column: The Consortium of Digital Forensics Specialists (CDFS)
}

Christopher Kelly

CDFS Board Chair

Follow this and additional works at: https://commons.erau.edu/jdfsl

Part of the Computer Engineering Commons, Computer Law Commons, Electrical and Computer Engineering Commons, Forensic Science and Technology Commons, and the Information Security Commons

\section{Recommended Citation}

Kelly, Christopher (2011) "Column: The Consortium of Digital Forensics Specialists (CDFS)," Journal of Digital Forensics, Security and Law: Vol. 6 : No. 3 , Article 1.

DOI: https://doi.org/10.15394/jdfsl.2011.1096

Available at: https://commons.erau.edu/jdfsl/vol6/iss3/1

This Article is brought to you for free and open access by

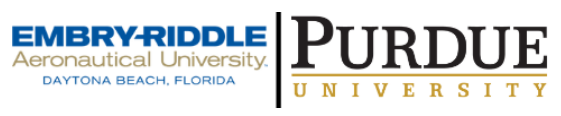
the Journals at Scholarly Commons. It has been accepted for inclusion in Journal of Digital Forensics, Security and Law by an authorized administrator of Scholarly Commons. For more information, please contact commons@erau.edu.

(c)ADFSL 


\title{
Column: The Consortium of Digital Forensics Specialists (CDFS)
}

\author{
Christopher Kelly \\ CDFS Board Chair
}

Digital forensic practitioners are faced with an extraordinary opportunity. In fact, we may never again be faced with such an opportunity, and this opportunity will challenge us in ways we may never again be challenged.

At this point in the history of the Digital Forensics profession, digital forensic specialists have the unique opportunity to help this profession emerge from its infancy. But for this profession to mature -- and to flourish -- individuals and organizations integral to the practice must assemble and shape its future. This is our opportunity. In fact, this is our mandate.

In 2008, a group of concerned digital forensic professionals recognized that state legislative initiatives requiring that digital forensic analysts become licensed as private investigators threatened the digital forensic profession. The group further recognized that states pushing these initiatives paid little or no regard to the individual credentials of the practitioner. These initiatives not only threatened the profession -- they threatened justice in the courts and inhibited access to qualified forensics professionals by individual consumers.

This grassroots group first decided to voice its collective opinion in North Carolina, where the Private Protective Services Board was considering mandating that digital forensic practitioners be licensed as private investigators. In April of 2008, three members of the group traveled to North Carolina and testified in opposition to the initiative. A significant lesson from the hearings was that digital forensics is a relatively new and segmented profession. Consequently, the group realized that digital forensic practitioners must unite and speak with a single voice on issues like regulation, standards, and licensing efforts.

During the summer of 2008, this group became the Consortium of Digital Forensic Specialists (CDFS). Later in 2008, CDFS worked closely with the American Bar Association's Section of Science and Technology to draft Resolution 301, a formal resolution in opposition to improper licensing initiatives.

CDFS realized however, that improper licensing initiatives were only one of many challenges facing digital forensic professionals. The profession was also challenged by: a lack of uniformly accepted standards; no accepted ethics model; and the absence of an umbrella organization to speak on the behalf of digital forensic professionals on important issues. 
In 2010, CDFS incorporated as a not-for-profit corporation with a single mission -- to serve the profession, our membership, and the community by providing leadership and advocacy as the global representative of the digital forensic profession. Our core objective is to assemble individuals and organizations at the table to discuss and debate critical issues in order to promote informed decisions about how to deal with them.

CDFS held a very successful public launch in August of 2011. As of the time of this writing, CDFS has more than 120 members from 34 states and 10 countries, and CDFS is working aggressively to bring more voices to the discussion forum. Several organizations -- including the Association of Digital Forensics, Security and Law -- have also already joined the CDFS.

CDFS is comprised of a Board of Directors and several committees. Our Board of Directors is comprised of several individual leaders in the digital forensic community. Board members bring extensive expertise and come from diverse sectors of the digital forensic community such as law enforcement, professional organizations, private practice, academia, training entities, certification organizations, and corporations.

Standing committees include the Advocacy Committee, Ethics Committee, and Standards Committee. These core committees will be responsible for significant work-product development. Each committee will be comprised of CDFS members who volunteer to take part in committee work. CDFS will provide the backbone collaboration technology to these committees to foster results. Upon completion of drafts of work-product, the membership at large will be invited to make comments before any further drafting or formal adoption. The membership will participate in the adoption process of any major initiative and/or work product through a voting process.

Established in September of 2011, the Ethics Committee is tasked with the implementation of an ethics blueprint. The blueprint calls for the development of ethics standards, a model ethical code, and ethics training. CDFS announced the creation of the Advocacy Committee in October of 2011. Contemporaneously, CDFS announced its' alliance with the American Bar Association's Section on Science and Technology. Under this alliance, CDFS will provide insight on digital forensic issues to the Section. The first order of business for the Advocacy Committee is to work in concert with the Section to develop a matrix of state private investigator licensing statutes and determine the impact of the statutes on digital forensic practitioners who seek to practice digital forensics within states that have such statutes.

As of the time of this writing, the CDFS Board is developing its Standards Committee. The Standards Committee will serve several critical purposes. The Committee will develop standards for digital forensics, as well as criteria for certifications, training, and other practices and procedures. 
CDFS' goals are both aggressive and broad. Implementation of projects may be slow and incremental in order to assure the highest-quality work-product and informed decision-making. All voices from all sectors of the industry are welcome to join CDFS. The CDFS Board believes that the best decisions are the product of diverse opinions, as well as an open, public and spirited debate. Our role as an umbrella organization will help us to promote debate, advocate, and serve our membership by acting as a clearing-house for information on the important topics that impact the digital forensic industry.

CDFS will serve the digital forensic community by serving as the umbrella organization for the profession. CDFS' mission is different from organizations dedicated to certification, proficiency, education, or training. CDFS will reach out to these organizations to arrange mutually beneficial relationships. CDFS recognizes that there are other organizations interested in establishing standards. But we also realize that if many different organizations have different standards, there is no standard at all. Our goal is to bridge the gap between organizations to develop cohesive standards appropriate to diverse sectors of the profession.

CDFS was formed because regulation and oversight of our industry is a reality, and we care about the future of this profession. We recognize the need to unite digital forensic professionals to influence this process in positive ways. This initiative grew from a grassroots volunteer effort to prevent private investigator licensing movements that hurt true digital forensic professionals, thwarted justice and hurt consumers. The licensing authorities of legislatures were concerned about protecting the public. They are wondering what digital forensic professionals will do to align themselves and demonstrate an ability to develop standards. Ours is a relatively new profession, and an umbrella organization is a necessary and critical next step in the maturation of the digital forensics industry. CDFS wants to make a difference by becoming this umbrella organization. With your assistance, we can strategically shape the profession so that it continues to thrive.

Individuals and organizations with an interest in participation in CDFS are invited to become members. Individual members have full participation and voting rights. Organizations are subject to a tiered membership matrix and also have full voting rights. Member organizations also receive derivative participation benefits for their digital forensic personnel or respective board members based upon their organization type (e.g., government, academic, nonprofit, or for-profit).

Membership dues fund backbone services and collaborative tools to help CDFS accomplish its mission. All CDFS board members and committee leaders are volunteers that dedicate themselves to the important causes identified in this article. For more information on CDFS membership, we invite you to visit our website at www.cdfs.org or email CDFS directly at membership@cdfs.org. 
Journal of Digital Forensics, Security and Law, Vol. 6(3) 